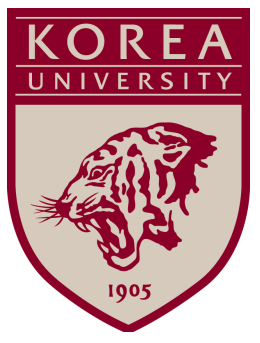

Discussion Paper Series

No. 1706

September 2017

\title{
Per Unit vs. Ad Valorem Royalty Licensing
}

Cuihong Fan Byoung Heon Jun Elmar G. Wolfstetter 


\title{
Per Unit vs. Ad Valorem Royalty Licensing*
}

\author{
Cuihong Fan $^{\dagger}$ \\ Shanghai University of Finance and Economics \\ cuihongf@mail.shufe.edu.cn
}

\author{
Byoung Heon Jun \\ Korea University, Seoul \\ bhjun@korea.ac.kr
}

\author{
Elmar G. Wolfstetter \\ Humboldt-University at Berlin and Korea University, Seoul \\ elmar.wolfstetter@rz.hu-berlin.de
}

July 10, 2017

\begin{abstract}
We consider the licensing of a non-drastic innovation by an innovator who interacts with a potential licensee in a downstream Cournot market. We compare two kinds of license contracts: per unit and ad valorem, combined with fixed fees. Assuming that antitrust authorities apply the same principle to review ad valorem royalty license contracts which they apply to per unit royalty license contracts, we show that per unit royalty licensing is more profitable if the licensor is more efficient in using the innovation, whereas ad valorem royalty licensing is more profitable if the licensee is more efficient. This explains why and when these licensing schemes should be observed.
\end{abstract}

KEYWORDS: Innovation, patent licensing, royalty contracts.

JEL CLASSIFICATIONS: D21, D43, D44, D45.

\section{Introduction}

Patent licensing of cost reducing innovations typically involves royalties combined with fixed fees. ${ }^{1}$ Royalties are predominantly linear in the licensees' output, revenue, or profit. These are generally referred to as per unit, ad valorem, and profit-share licensing. All these schemes serve the purpose to alleviate the downward pressure on price induced by the reduction in licensees' cost that is associated with the transfer of superior technology.

Royalties may, of course, be misused to achieve collusive outcomes. In the extreme, they can be used to implement a monopoly outcome, either making the licensee or the licensor a monopoly, whichever allows the highest extraction of surplus. This is why antitrust authorities interfere if they suspect schemes that are geared to raise the equilibrium price. The literature on per unit royalty licensing has captured this interference by requiring that royalty rates cannot exceed the cost reduction induced by the transfer of technology.

\footnotetext{
${ }^{*}$ Research support by Korea University (Grant: K1710011) and the National Natural Science Foundation of China (Grant: 71371116) is gratefully acknowledged.

${ }^{\dagger}$ Corresponding author. School of Economics, Shanghai University of Finance and Economics, 777 Guoding Road, Shanghai 200433, China.

${ }^{1}$ The empirical evidence is reviewed, for example, in Rostoker (1984), Taylor and Silberston (1973), Brousseau, Coeurderoy, and Chaserant (2007), and Vishwasrao (2007).
} 
The theoretical literature has almost exclusively focused on per unit royalties, in particular in the case when the innovator is an incumbent firm that competes with potential licensees. The analysis of patent licensing by an incumbent firm was pioneered by Katz and Shapiro (1985). Later, Wang (1998) showed that there is a sharp distinction between the licensing of a non-drastic innovation by an outside patent holder, who is not a player in the potential licensee's market game, and an incumbent patent holder who is a competitor in the product market of potential licensees. Whereas outside innovators are advised to auction patent licenses to a limited number of licensees (see Kamien, 1992; Kamien, Oren, and Tauman, 1992; Sen and Tauman, 2007), inside patent holders are advised to employ per unit royalty contracts without fixed fees. ${ }^{2}$

However, the empirical literature indicates that ad valorem royalties are equally if not more widely used. In a sample of 286 French license contracts, Bousquet, Crémer, Ivaldi, and Wolkowicz (1998) found that $78 \%$ included royalties among which all but 9 used ad valorem royalties. This suggests that the theoretical literature should pay due attention to different royalty schemes and identify testable conditions that explain when either per unit or ad valorem royalties should be observed.

The analysis of ad valorem royalties by an inside innovator was initiated by San Martín and Saracho $(2010)^{3}$ who considered a linear model and showed that "... in the classical ... Cournot duopoly an internal patentee will always prefer the ad valorem royalty to a per unit royalty". ${ }^{4}$ However, their analysis assumes a particular cost profile induced by the transfer of technology and does not assume that antitrust authorities apply the same principle to review ad valorem royalty licensing which they apply to per unit royalty licensing.

In the present paper we compare the profitability of per unit and ad valorem royalty licensing, assuming consistent antitrust interference. Unlike the literature, our analysis is not restricted to the case of linear demand, and we allow for all possible cost profiles induced by the transfer of technology. We identify testable conditions that explain when either per unit or ad valorem royalties should be observed.

The plan of the paper is as follows: In Section 2 we state the model. In Section 3 we derive some crucial properties of the oligopoly subgames induced by royalty licensing. In Section 4 we prove testable conditions for the optimality of either per unit or ad valorem royalty licensing. In Section 5 we close with a brief summary.

\section{Model}

Consider a dynamic licensing game between an incumbent innovator who owns a cost reducing innovation and one competitor who operates in the same product market. In the first stage, the incumbent offers a license contract in the form of a two-part tariff that prescribes either a per unit royalty rate, $r$, or an ad valorem royalty rate, $s$, together with a fixed fee, $f$. In the second stage, after the license contract has been either accepted or rejected, the two firms play a Cournot market game.

\footnotetext{
${ }^{2}$ However, Giebe and Wolfstetter (2008) and Fan, Jun, and Wolfstetter (2013) show that an outside innovator can increase his payoff by supplementing license auctions with per unit royalty contracts for those who lose the auction, and Poddar and Sinha (2010) and Fan, Jun, and Wolfstetter (2017) show at different levels of generality that an inside innovator can generally increase his payoff by employing two-part tariffs rather than pure royalty contracts.

${ }^{3}$ Earlier, Bousquet, Crémer, Ivaldi, and Wolkowicz (1998) already considered ad valorem royalty licensing by an outside innovator.

${ }^{4}$ Similarly, Heywood, Li, and Ye (2014) compare per unit and ad valorem royalties in a binary model of incomplete information with linear demand. They use simulations to show that ad valorem royalties may be more profitable than per unit royalties.
} 
Firms are indexed by $i \in\{0,1\}$ where firm 0 is the incumbent innovator and firm 1 the potential licensee. Prior to licensing, firms' unit costs are $\left(c_{0}, c_{1}\right)=(d, c)$, with $0<d<c$. Licensing reduces the unit cost of firm 1 to $0<x<c$. Either the licensee or the licensor may make better use of the innovation, and we call firm 0 "more efficient" if $x>d$ and firm 1 "more efficient" if $x<d$.

The innovation is non-drastic, i.e., the exclusive use of the innovation does not give rise to a monopoly. ${ }^{5}$

The payoff functions of the oligopoly subgames under per unit and ad valorem royalty licensing are:

$$
\begin{array}{ll}
\pi_{0}^{r}\left(q_{0}, q_{1}\right):=(P(Q)-d) q_{0}+r q_{1}+f_{r} & \pi_{1}^{r}\left(q_{1}, q_{0}\right):=(P(Q)-x-r) q_{1}-f_{r} \\
\pi_{0}^{s}\left(q_{0}, q_{1}\right):=(P(Q)-d) q_{0}+s P(Q) q_{1}+f_{s} & \pi_{1}^{s}\left(q_{1}, q_{0}\right):=((1-s) P(Q)-x) q_{1}-f_{s} .
\end{array}
$$

There $Q:=q_{0}+q_{1}$ and $P(Q)$ is the inverse demand function which is decreasing and concave.

License contracts are regulated by antitrust authorities that interfere if they suspect collusive schemes that are geared to raise the equilibrium price. We capture these regulations by requiring that licensing cannot raise the equilibrium price above the level $p^{N}$ that prevails without licensing:

$$
P(Q) \leq p^{N} \quad \text { (antitrust constraints). }
$$

In the case of per unit royalties, (3) is equivalent to the usual requirement that the royalty rates cannot exceed the cost reduction, $r \leq c-x$.

As Niu (2013) pointed out in an insightful paper on the equivalence of per unit and profit-share licensing, (3) correspond to the "upward pressure" (UPP) methodology in merger policy that approve mergers only if the upward pressure on price due to the change in market structure is compensated by a downward pressure due to efficiency gains (see Farrell and Shapiro, 2010). Therefore, (3) assume that antitrust authorities apply the same principle to review license contracts which they apply to review mergers.

Adding the usual boundary constraints, $r \geq 0, s \in[0,1]$, the sets of feasible royalty rates are: $R:=\left\{r \in \mathbb{R}_{+} \mid P\left(Q^{r}(r)\right) \leq p^{N}\right\}=\left\{r \in \mathbb{R}_{+} \mid r \leq c-x\right\}, S:=\left\{s \in \mathbb{R}_{+} \mid s \leq 1, P\left(Q^{s}(s)\right) \leq p^{N}\right\}$.

The licensor adopts the most profitable licensing scheme among all license contracts, $\left(r, f_{r}\right),\left(s, f_{s}\right)$, that satisfy feasibility and assure voluntary participation.

\section{Properties of the oligopoly subgames}

To prepare the ranking of the profitability of the two licensing schemes, we first characterize some properties of the downstream oligopoly subgames induced by licensing. These results culminate in Lemma 2 that plays a key role in the proof of our main results in Section 4.

For all given $r \in R$ and $s \in S$, the equilibrium solutions of the oligopoly subgames are: $q_{i}^{s}(s):=$ $\arg \max _{q \geq 0} \pi_{i}^{s}\left(q, q_{j}^{s}(s)\right), q_{i}^{r}(r):=\arg \max _{q \geq 0} \pi_{i}^{r}\left(q, q_{j}^{r}(r)\right)$. From the first order conditions, one ob-

\footnotetext{
${ }^{5}$ This requires that the monopoly price at unit cost $d$ exceeds $c$ and the monopoly price at unit cost $x$ exceeds $d$.
} 
tains:

$$
\begin{gathered}
q_{0}^{s}(s)=\max \left\{\frac{(1-s)^{2} P\left(Q^{s}(s)\right)-(1-s) d+s x}{-(1-s) P^{\prime}\left(Q^{s}(s)\right)}, 0\right\} \\
q_{1}^{s}(s)=\max \left\{\frac{(1-s) P\left(Q^{s}(s)\right)-x}{-(1-s) P^{\prime}\left(Q^{s}(s)\right)}, 0\right\}, \quad Q^{s}(s):=q_{0}^{s}(s)+q_{1}^{s}(s) \\
q_{0}^{r}(r)=\frac{P\left(Q^{r}(r)\right)-d}{-P^{\prime}\left(Q^{r}(r)\right)}, \quad q_{1}^{r}(r)=\frac{P\left(Q^{r}(r)\right)-(x+r)}{-P^{\prime}\left(Q^{r}(r)\right)}, \quad Q^{r}(r):=q_{0}^{r}(r)+q_{1}^{r}(r) .
\end{gathered}
$$

Because the innovation is non-drastic, $\left(q_{0}^{r}(r), q_{1}^{r}(r)\right)$ is an interior solution for all $r \in R$; however, $\left(q_{0}^{s}(s), q_{1}^{s}(s)\right)$ can be a corner solution for some $s \in S$.

Let $\hat{q}_{1}(s)$ denote the smallest $q_{1}$ that makes the best reply output of firm 0 equal to zero, which is the unique solution of the equation: $(1-s)^{2} P\left(q_{1}\right)-(1-s) d+s x=0$.

Also let $q_{1}^{M}(s)$ denote firm 1's monopoly output given $s$, i.e., firm 1's best response to $q_{0}=0$, which is the unique solution of the equation: $(1-s) P\left(q_{1}\right)+(1-s) q_{1} P^{\prime}\left(q_{1}\right)-x=0$. Then $q_{0}^{s}(s)=0$ if and only if $\hat{q}_{1}(s) \leq q_{1}^{M}(s)$ and, in that case, $Q^{s}(s)=q_{1}^{M}(s)$.

Finally denote firm 0 's monopoly output by $q_{0}^{M}$, which is firm 0 's best response to $q_{1}=0$. Because $\left(q_{0}^{s}(s), q_{1}^{s}(s)\right)$ lies on the graph of firm 0's best response function and firm 0's best response function has slope larger than -1 , we know that $Q^{s}(s)=q_{0}^{s}(s)+q_{1}^{s}(s) \geq q_{0}^{M}$. Furthermore $Q^{s}(s)=q_{0}^{M}$ for $s$ close to 1 because firm 1's revenue would not cover the cost unless $x=0$. Of course, $q_{1}^{s}(s)>0$ whenever $Q^{s}(s)>q_{0}^{M}$.

Lemma 1. $Q^{s}(s)$ and $Q^{r}(r)$ are strictly decreasing for all $r \in R, s \in S$.

Proof. Because $\left(q_{0}^{r}(r), q_{1}^{r}(r)\right)$ is an interior solution for all $r \in R$, from the first order conditions for $q_{0}^{r}(r), q_{1}^{r}(r)$ one finds: $P^{\prime}\left(Q^{r}(r)\right) Q^{r}(r)+2 P\left(Q^{r}(r)\right)-d-x-r=0$. Differentiating with respect to $r$ yields:

$$
\partial_{r} Q^{r}(r)=\frac{1}{3 P^{\prime}\left(Q^{r}(r)\right)+Q^{r}(r) P^{\prime \prime}\left(Q^{r}(r)\right)}<0
$$

Hence $Q^{r}(r)$ is strictly decreasing.

Because $P\left(Q^{s}(s)\right) \leq p^{N}$, we have $Q^{s}(s) \geq Q^{N}>q_{0}^{M}$, where $Q^{N}$ is the duopoly output without licensing. Thus we have either an interior solution or $q_{0}^{s}(s)=0$ and $Q^{s}(s)=q_{1}^{M}(s)$. If $\left(q_{0}^{s}(s), q_{1}^{s}(s)\right)$ is an interior solution, then, by a similar procedure as above, one has:

$$
\partial_{s} Q^{s}(s)=\frac{P\left(Q^{s}(s)\right)}{(3-s) P^{\prime}\left(Q^{s}(s)\right)+Q^{s}(s) P^{\prime \prime}\left(Q^{s}(s)\right)}<0 .
$$

Hence $Q^{s}(s)$ is strictly decreasing in this case.

If $q_{0}^{s}(s)=0$, then $Q^{s}(s)=q_{1}^{M}(s)$ is also strictly decreasing:

$$
\partial_{s} q_{1}^{M}(s)=\frac{x}{(1-s)^{2}\left(2 P^{\prime}\left(q_{1}^{M}(s)\right)+q_{1}^{M}(s) P^{\prime \prime}\left(q_{1}^{M}(s)\right)\right)}<0 .
$$

Because $Q^{s}(s)$ is continuous regardless of whether the solution is in the interior or on the boundary, we conclude that $Q^{s}(s)$ is strictly decreasing. 
We are now ready to prove the following Lemma that plays a key role in our constructive proof of our main results.

Lemma 2. 1) For each $s \in S$ there exists an $r \in R$ that induces $P\left(Q^{s}(s)\right)=P\left(Q^{r}(r)\right)$, and vice versa, and 2) for these royalty rates $q_{0}^{r}(r)>q_{0}^{s}(s)$ and $q_{1}^{s}(s)>q_{1}^{r}(r)$ in such a way that $q_{0}^{r}(r)-q_{0}^{s}(s)=$ $q_{1}^{s}(s)-q_{1}^{r}(r)$.

Proof. It is clear from Lemma 1 that $P_{R}:=\left\{P\left(Q^{r}(r)\right) \mid r \in R\right\}=\left[P\left(Q^{r}(0)\right), p^{N}\right]$ and that there is a unique $s^{N}$ such that $Q^{s}\left(s^{N}\right)=Q^{N}$. Thus we have $P_{S}:=\left\{P\left(Q^{s}(s)\right) \mid s \in S\right\}=\left[P\left(Q^{s}(0)\right), p^{N}\right]$. We have $P_{S}=P_{R}$ because $P\left(Q^{s}(0)\right)=P\left(Q^{r}(0)\right)$, which proves that for each $s$ there exists an $r$ that induces $P\left(Q^{s}(s)\right)=P\left(Q^{r}(r)\right)$.

Of course, $P\left(Q^{r}(r)\right)=P\left(Q^{s}(s)\right) \Rightarrow Q=Q^{r}(r)=Q^{s}(s) \Rightarrow q_{0}^{r}(r)-q_{0}^{s}(s)=q_{1}^{s}(s)-q_{1}^{r}(r)$. If $\left(q_{0}^{s}(s), q_{1}^{s}(s)\right)$ is an interior solution one can easily confirm from (4)-(6) that:

$$
q_{0}^{r}(r)-q_{0}^{s}(s)=\frac{s((1-s) P(Q)-x)}{-(1-s) P^{\prime}(Q)}=s q_{1}^{s}(s)>0, \quad \text { because } Q>q_{0}^{M} .
$$

If $q_{0}^{s}(s)=0$, it is clear that $q_{0}^{r}(r)>q_{0}^{s}(s)$.

Also note that $Q^{r}(r)=Q^{s}(s)=Q$ implies $r=s P(Q)$.

\section{Profitability ranking}

The licensor chooses the licensing scheme that maximizes his payoff, which is equal to his own profit plus his royalty income.

No matter which $r$ respectively $s$ is chosen, it is optimal for the licensor to set the highest fixed fee that assures voluntary participation by the licensee. Therefore,

$$
\begin{aligned}
& f_{r}=\left(P\left(Q^{r}(r)\right)-x\right) q_{1}^{r}(r)-r q_{1}^{r}(r)-\pi_{1}^{N} \\
& f_{s}=\left(P\left(Q^{s}(s)\right)-x\right) q_{1}^{s}(s)-s P\left(Q^{s}(s)\right) q_{1}^{s}(s)-\pi_{1}^{N},
\end{aligned}
$$

where $\pi_{1}^{N}$ denotes the equilibrium profit of firm 1 if no licensing occurs.

Substituting (10) and (9) into the licensor's payoff functions stated in (1), (2) yields the licensor's objective functions:

$$
\begin{aligned}
& \Pi_{0}^{r}(r)=P\left(Q^{r}(r)\right) Q^{r}(r)-\left(d q_{0}^{r}(r)+x q_{1}^{r}(r)\right)-\pi_{1}^{N} \\
& \Pi_{0}^{s}(s)=P\left(Q^{s}(s)\right) Q^{s}(s)-\left(d q_{0}^{s}(s)+x q_{1}^{s}(s)\right)-\pi_{1}^{N} .
\end{aligned}
$$

Let $s^{*}:=\arg \max _{s \in S} \Pi^{s}(s)$ and $r^{*}:=\arg \max _{r \in R} \Pi^{r}(r)$, and we find the following necessary and sufficient conditions for the optimality of per unit vs. ad-valorem royalty licensing, depending on whether licensee or licensor can make better use of the innovation.

Proposition 1 (Profitability ranking). Suppose $r^{*}>0$. Then,

$$
x \gtreqless d \Longleftrightarrow \Pi^{r}\left(r^{*}\right) \gtreqless \Pi^{s}\left(s^{*}\right) .
$$

If $r^{*}=0$, the only change is that $\Pi^{r}\left(r^{*}\right)$ can be equal to $\Pi^{s}\left(s^{*}\right)$ even if $x<d$. 
Proof. First, assume $r^{*}>0$.

1) Suppose $x>d$. Choose $r$ in such a way that $P\left(Q^{r}(r)\right)=P\left(Q^{s}\left(s^{*}\right)\right)$, which is possible by Part 1 of Lemma 2. Then, by Part 2 of Lemma 2:

$$
\begin{aligned}
(d-x)\left(q_{0}^{r}(r)-q_{0}^{s}\left(s^{*}\right)\right)<0 & \Rightarrow d\left(q_{0}^{r}(r)-q_{0}^{s}\left(s^{*}\right)\right)-x\left(q_{1}^{s}(s)-q_{1}^{r}(r)\right)<0 \\
& \Rightarrow d q_{0}^{r}(r)+x q_{1}^{r}(r)<d q_{0}^{s}\left(s^{*}\right)+x q_{1}^{s}\left(s^{*}\right),
\end{aligned}
$$

which implies $\Pi^{s}\left(s^{*}\right)<\Pi^{r}(r) \leq \Pi^{r}\left(r^{*}\right)$.

2) Suppose $x=d$. Now choose $s$ in such a way that $P\left(Q^{s}(s)\right)=P\left(Q^{r}\left(r^{*}\right)\right)$. Then, by Part 2 of Lemma 2 we have

$$
(d-x)\left(q_{0}^{r}\left(r^{*}\right)-q_{0}^{s}(s)\right)=0 \Rightarrow d q_{0}^{r}\left(r^{*}\right)+x q_{1}^{r}\left(r^{*}\right)=d q_{0}^{s}(s)+x q_{1}^{s}(s),
$$

which implies $\Pi^{r}\left(r^{*}\right)=\Pi^{s}(s) \leq \Pi^{s}\left(s^{*}\right)$. Similarly, one has $\Pi^{r}\left(r^{*}\right) \geq \Pi^{s}\left(s^{*}\right)$, thus $\Pi^{r}\left(r^{*}\right)=$ $\Pi^{s}\left(s^{*}\right){ }^{6}$

3) Suppose $x<d$. Again choose $s$ in such a way that $P\left(Q^{s}(s)\right)=P\left(Q^{r}\left(r^{*}\right)\right)$. Because $r=s P(Q)$, $r^{*}>0 \Rightarrow s>0$. Therefore, by Part 2 of Lemma 2:

$$
\begin{aligned}
(d-x)\left(q_{0}^{r}\left(r^{*}\right)-q_{0}^{s}(s)\right)>0 & \Rightarrow d\left(q_{0}^{r}\left(r^{*}\right)-q_{0}^{s}(s)\right)-x\left(q_{1}^{s}(s)-q_{1}^{r}\left(r^{*}\right)\right)>0 \\
& \Rightarrow d q_{0}^{r}\left(r^{*}\right)+x q_{1}^{r}\left(r^{*}\right)>d q_{0}^{s}(s)+x q_{1}^{s}(s),
\end{aligned}
$$

which implies $\Pi^{r}\left(r^{*}\right)<\Pi^{s}(s) \leq \Pi^{s}\left(s^{*}\right)$.

4) Evidently, by the law of contraposition, 1) - 3) also imply that $\Pi^{r}\left(r^{*}\right) \gtreqless \Pi^{s}\left(s^{*}\right) \Rightarrow x \gtreqless d$.

Finally, suppose $r^{*}=0$. Then, $x<d$ implies only the weaker relationship: $\Pi^{s}\left(s^{*}\right) \geq \Pi^{s}(0)=$ $\Pi^{r}\left(r^{*}\right)$.

Our results have an intuitive explanation, although the proof involved some subtle distinctions. Whereas per unit royalties serve the purpose to restrict the licensee's output, ad valorem royalties restrict the own output of the licensor. If the licensor is more efficient, it is in the interest of the licensor to indirectly shift output to himself by restricting the output of the licensee by means of per unit royalties. Whereas, if the licensee is more efficient, it is in the interest of the licensor to indirectly shift output to the licensee by restricting the own output (and extract surplus with the fixed fee), by means of ad valorem royalties.

\section{Conclusion}

We have shown that per unit royalty licensing is more profitable if the licensor is more efficient in using the innovation, whereas ad valorem licensing is more profitable if the licensee is more efficient. These results may explain why both types of licensing are widely used and under which conditions one should observe either the one or the other.

The literature that claimed that ad valorem licensing is unconditionally more profitable than per unit licensing considered a linear model with a particular cost profile induced by the innovation and failed to assume that antitrust authorities apply the same principle to review ad valorem royalty licensing which they apply to per unit royalty licensing.

\footnotetext{
${ }^{6}$ Niu already noted that, contrary to San Martín and Saracho (2010, 2015), per unit and ad valorem licensing are equally profitable if $x=d$ and demand is linear. He comments: “... San Martín and Saracho adopted a uniform licensing policy ... imposing the same constraint, $f \geq 0$, on different licensing forms ... Under per unit royalty licensing $f \geq 0$ is equivalent to $[r \leq c-x] \ldots$, but under ... ad valorem licensing there is no sound economic explanation to this constraint" (Niu, 2013, p. 14).
} 


\section{References}

Bousquet, A., H. Crémer, M. Ivaldi, and M. Wolkowicz (1998). "Risk Sharing in Licensing". International Journal of Industrial Organization 16, pp. 535-554.

Brousseau, E., R. Coeurderoy, and C. Chaserant (2007). "The Governance of Contracts: Empirical Evidence on Technology Licensing Agreements". Journal of Institutional and Theoretical Economics 163, pp. 205-235.

Fan, C., B. Jun, and E. Wolfstetter (2013). "Licensing Process Innovations when Losers' Messages Determine Royalty Rates". Games and Economic Behavior 82, pp. 388-402.

- (2017). Optimal Licensing under Incomplete Information: The Case of the Inside Patent Holder. SSRN Discussion Paper, http://dx.doi.org/10.2139/ssrn.2935589.

Farrell, J. and C. Shapiro (2010). "Antitrust Evaluation of Horizontal Mergers: An Economic Alternative to Market Definition". B.E. Journal of Theoretical Economics 10 (Article 9).

Giebe, T. and E. Wolfstetter (2008). "License Auctions with Royalty Contracts for (Winners and) Losers". Games and Economic Behavior 63, pp. 91-106.

Heywood, J., J. Li, and G. Ye (2014). "Per Unit vs. Ad Valorem Royalties under Asymmetric Information". International Journal of Industrial Organization 37, pp. 38-46.

Kamien, M. I. (1992). "Patent Licensing". Handbook of Game Theory. Ed. by R. Aumann and S. Hart. Vol. I. Elsevier Science, pp. 331-354.

Kamien, M. I., S. Oren, and Y. Tauman (1992). "Optimal Licensing of Cost-Reducing Innovation". Journal of Mathematical Economics 21, pp. 483-508.

Katz, M. and C. Shapiro (1985). "On the Licensing of Innovations". RAND Journal of Economics 16.4, pp. 504-520.

Niu, S. (2013). "The Equivalence of Profit-Sharing Licensing and Per-Unit Royalty Licensing". Economic Modelling 32, pp. 10-14.

Poddar, S. and U. Sinha (2010). "Patent Licensing from a High-Cost Firm to a Low-Cost Firm". The Economic Record 86, pp. 384-395.

Rostoker, M. (1984). “A Survey of Corporate Licensing”. IDEA 24, pp. 59-92.

San Martín, M. and A. Saracho (2010). "Royalty Licensing”. Economics Letters 107, pp. 284-287.

- (2015). "Optimal Two-Part Tariff Licensing Mechanisms". The Manchester School 83, pp. 288 306.

Sen, D. and Y. Tauman (2007). "General Licensing Schemes for a Cost-Reducing Innovation". Games and Economic Behavior 59, pp. 163-186.

Taylor, C. and Z. Silberston (1973). The Economic Impact of the Patent System. Cambridge University Press.

Vishwasrao, S. (2007). "Royalties vs. Fees: How do Firms Pay for Foreign Technology?" International Journal of Industrial Organization 25, pp. 741-759.

Wang, X. H. (1998). "Fee versus Royalty Licensing in a Cournot Duopoly Model". Economics Letters 60, pp. 55-62. 